\title{
The bio operon on the acquired symbiosis island of Mesorhizobium sp. strain R7A includes a novel gene involved in pimeloyl-CoA synthesis
}

\author{
John T. Sullivan, ${ }^{1}$ Steven D. Brown, ${ }^{1}$ R. Rogers Yocum ${ }^{2}$ \\ and Clive W. Ronson ${ }^{1}$ \\ Author for correspondence: Clive W. Ronson. Tel: +64 3 4797701. Fax: +64 34798540. \\ e-mail: clive.ronson@stonebow.otago.ac.nz
}

1 Department of

Microbiology, University of

Otago, PO Box 56,

Dunedin, New Zealand

2 OmniGene Bioproducts Inc., Cambridge, MA 02138, USA
The symbiosis island of Mesorhizobium sp. strain R7A is a 500 kb chromosomal genetic element that upon transfer converts nonsymbiotic mesorhizobia to symbionts able to nodulate and fix nitrogen with Lotus corniculatus. Four genomic species of nonsymbiotic mesorhizobia have been isolated. All were auxotrophic for thiamin and biotin and three were auxotrophic for nicotinate, whereas derivatives of the strains containing the symbiosis island were prototrophic for all three vitamins. In this work, a $13.2 \mathrm{~kb}$ region of the island that converts the nonsymbionts to nicotinate and biotin prototrophy was characterized. The region contained orthologues of the Escherichia coli bioBFD and $A$ genes arranged in an operon with a novel gene, bioZ, a nadABC operon, the nitrogen-fixation regulatory gene nif $A$, and a homologue of the pantothenate biosynthesis gene panD. The bioz gene product was similar to $\beta$-ketoacyl-acyl carrier protein synthase III (FabH). bioZ::Tn5 mutants grew poorly in the absence of biotin and the bioZ gene complemented an E. coli bioH mutant, suggesting that its product is involved in the synthesis of pimeloylCoA. The bio operon was not required for symbiosis, as only mutants in the nifA gene were impaired in symbiosis, and a bioA::Tn5 mutant was not impaired in rhizosphere colonization. The rationale for the vitamin biosynthetic loci being located on an acquired genetic element that is absent from nonsymbiotic mesorhizobia remains to be determined.

Keywords: biotin biosynthesis, $\beta$-ketoacyl-acyl carrier protein synthase III, horizontal gene transfer

\section{INTRODUCTION}

In Mesorhizobium sp. strain R7A, the majority of the symbiosis genes are contained on a $500 \mathrm{~kb}$ chromosomal genetic element termed a symbiosis island. The island transfers to nonsymbiotic mesorhizobia present in the environment and converts them to symbionts able to nodulate Lotus corniculatus and Lotus japonicus. The island integrates into a phe-tRNA gene, reconstructing the gene at the left end and forming a $17 \mathrm{bp}$ direct repeat

\section{Abbreviation: NMN, nicotinic acid mononucleotide.}

The GenBank accession number for the sequence reported in this paper is AF311738. of the $3^{\prime}$ end of the gene at the right end (Sullivan et al., 1995 ; Sullivan \& Ronson, 1998).

The symbiosis island was discovered in a population of mesorhizobia nodulating a stand of L. corniculatus planted 7 years earlier. The stand was established with a single inoculant Mesorhizobium strain, ICMP 3153, in tussock grassland devoid of naturalized rhizobia capable of nodulating the plant. Genetically diverse mesorhizobia recovered from nodules from the stand all contained identical symbiotic DNA, suggesting that they arose through transfer of symbiotic DNA from the inoculant strain to nonsymbiotic rhizobia present at the site. The symbiotic DNA was located on the chromosome of the strains (Sullivan et al., 1995). Subsequently, seven nonsymbiotic strains that belonged to four 
genomic species of mesorhizobia were isolated from the site where the diverse symbionts were discovered. Phenotypic characterization of the nonsymbionts revealed that they were auxotrophic for biotin and thiamin and all but one were auxotrophic for nicotinate. In contrast, ICMP 3153, R7A, which is a field reisolate of ICMP 3153, and the diverse symbionts were prototrophic for all three vitamins, suggesting that the island contained genes required for vitamin synthesis (Sullivan et al., 1996). Transfer of the symbiosis island from R7A to nonsymbionts in the laboratory was subsequently demonstrated using selection for prototrophy (Sullivan \& Ronson, 1998).

Little is known about vitamin synthesis and metabolism in rhizobia. Individual strains of some species require one or more of pantothenate, thiamin and biotin for growth, and Azorhizobium caulinodans also requires nicotinate (Dreyfus et al., 1983; Graham, 1963). Loci required for thiamin synthesis are located on plasmids in Sinorhizobium meliloti and Rhizobium etli (Finan et al., 1986; Miranda-Rios et al., 1997). An early study of the biotin requirements of several rhizobial species suggested that rhizobia could be divided into prototrophs, auxotrophs and bradytrophs, strains which grow poorly in continuous serial culture in biotin-free media (Wilson \& Wilson, 1942). Recent studies carried out using $S$. meliloti suggested that both synthesis and uptake of biotin promote rhizosphere colonization (Streit \& Phillips, 1996). The association of vitamin loci with acquired genetic elements, some of which contain known symbiotic genes, together with the results of Streit et al. (1996) suggest that the loci may play an important role in the plant-microbe interaction. However, the fact that some wild-type symbiotic rhizobia are vitamin auxotrophs counters this suggestion.

Here we present the analysis of a $13.2 \mathrm{~kb}$ region of the Mesorbizobium loti symbiosis island that contains operons required for the syntheses of nicotinic acid mononucleotide (NMN) and biotin. The bio operon included a novel gene, designated bioZ, which was implicated in the synthesis of the biotin precursor pimeloyl-CoA. The region also contained a nifA gene required for nitrogen fixation. The vitamin loci were not required for symbiotic nitrogen fixation or for rhizosphere colonization.

\section{METHODS}

Strains and plasmids. The bacterial strains and plasmids used in this study are described in Table 1. Escherichia coli strains were cultured at $37^{\circ} \mathrm{C}$ in either Luria-Bertani (LB) medium or M9 minimal medium supplemented with thiamin at $1 \mu \mathrm{g} \mathrm{ml}^{-1}$ and avidin at $1 \mu \mathrm{g} \mathrm{ml}^{-1}$ when required. Mesorhizobial strains were grown at $28{ }^{\circ} \mathrm{C}$ in TY (Beringer, 1974) or RDM media (Ronson et al., 1987) with $10 \mathrm{mM}$ glucose (G/RDM) and supplemented with $1 \mu \mathrm{g}$ thiamin $\mathrm{ml}^{-1}, 1 \mu \mathrm{g}$ nicotinic acid $\mathrm{ml}^{-1}$ and $20 \mathrm{ng}$ biotin $\mathrm{ml}^{-1}$. For vitamin auxotrophy studies, G/ RDM was solidified with Noble agar $(1.5 \%, w / v ;$ Difco) and supplemented with combinations of the three vitamins. In experiments to assess the growth requirements for biotin, avidin (10 $\mathrm{ng} \mathrm{ml}^{-1}$ for mesorhizobia; $1 \mu \mathrm{g} \mathrm{ml}^{-1}$ for E. coli) was also added. Media were supplemented with antibiotics as required at the following concentrations: for E. coli, $100 \mu \mathrm{g}$ ampicillin $\mathrm{ml}^{-1}, 50 \mu \mathrm{g}$ kanamycin $\mathrm{ml}^{-1}, 25 \mu \mathrm{g}$ gentamicin $\mathrm{ml}^{-1}$ and $15 \mu \mathrm{g}$ tetracycline $\mathrm{ml}^{-1}$; for mesorhizobia, $200 \mu \mathrm{g}$ neomycin $\mathrm{ml}^{-1}, 50 \mu \mathrm{g}$ gentamicin $\mathrm{ml}^{-1}$ and $2 \mu \mathrm{g}$ tetracycline $\mathrm{ml}^{-1}$.

DNA manipulations. Mesorhizobium genomic DNA was prepared as previously described (Sullivan et al., 1995). Plasmid DNA extraction, agarose gel electrophoresis, cloning and electroporation were carried out using established methods (Sambrook et al., 1989). Southern blotting was carried out by capillary transfer. DNA probes were labelled by random priming and hybridized using standard conditions (Sambrook et al., 1989; Sullivan et al., 1995). Following hybridization, membranes were washed sequentially at $65^{\circ} \mathrm{C}$ in $2 \times \mathrm{SSC} / 0 \cdot 1 \%$ SDS, $1 \times \mathrm{SSC} / 0 \cdot 1 \%$ SDS and $0 \cdot 1 \times \mathrm{SSC} /$ $0 \cdot 1 \%$ SDS.

DNA sequencing. EcoRI and Pst I fragments of p637 were subcloned into pUC19, and the plasmid templates were sequenced using universal M13 forward and reverse sequencing primers and custom primers. Other primers used included a Tn5-specific sequencing primer, 5' -CGTTCAGGACGCTACTT-3'. Sequencing was carried out using thermal cycle sequencing and an Applied Biosystems model 377 autosequencer. The sequence was assembled using the Seqman package (DNASTAR, Madison, WI). Open reading frames (ORFs) likely to encode genes were identified using Genemark.hmm utilizing a heuristically derived model (Besemer \& Borodovsky, 1999), and through database searches using BLAST version 2.0 (Altschul et al., 1997).

Tn5 mutagenesis. An E. coli HB101 clone containing cosmid p637 was mutagenized with Tn5 using phage 2467 (de Bruijn \& Lupski, 1984). After phage infection, Tn 5 insertions in $p 637$ were selected by preparing cosmid DNA from pooled $\mathrm{Km}^{\mathrm{r}} \mathrm{Tc}^{\mathrm{r}}$ mutants, transforming this DNA by electroporation into HB101 and selecting for $\mathrm{Km}^{\mathrm{r}} \mathrm{Tc}^{\mathrm{r}}$ transformants. The positions of Tn5 insertions were mapped by restriction endonuclease analysis and by cloning BamHI or EcoRI-BamHI fragments containing the arms of Tn5 into pUC19 and sequencing these clones using the Tn5-specific primer. Marker exchange of Tn5 insertions into strain R7A was forced by plasmid incompatibility using pPH1JI (Ruvkun \& Ausubel, 1981). To confirm that the exchange had occurred, genomic DNA was prepared from the putative R7A:: Tn5 mutants, digested with EcoRI, blotted and probed successively with p637 and p239.

Bacterial crosses. Crosses were carried out by triparental spot matings on TY plates using the helper plasmid pRK2013 in HB101 (Ditta et al., 1980) and using HB101 donor strains. Mesorhizobium transconjugants were selected on G/RDM media supplemented with appropriate antibiotics.

Nodulation tests and symbiotic phenotype. Nodulation tests were carried out using L. corniculatus as described by Vincent (1970). Uninoculated plants and plants inoculated with strain R7A were used as controls. After 2 weeks, plants were scored for the presence of nodules. After 6 weeks, shoot length and shoot wet weight were measured. No significant difference in shoot weight or shoot length in comparison to uninoculated controls indicated an ineffective $\left(\mathrm{Fix}^{-}\right)$symbiosis.

Rhizosphere colonization studies. Inocula were prepared from $48 \mathrm{~h}$ cultures grown in G/RDM media supplemented with $1 \mathrm{ng}$ biotin $\mathrm{ml}^{-1}$. The cells were washed and diluted, and viable counts were performed as described by Streit et al. (1996). L. corniculatus seeds were surface-sterilized and germinated as described by Vincent (1970). Individual 2-d-old seedlings were transferred into modified Leonard jars containing vermiculite and $0.25 \times$ Hoagland's solution, inocu- 
Table 1. Strains and plasmids

\begin{tabular}{|c|c|c|}
\hline Strain or plasmid & Relevant properties & Reference \\
\hline \multicolumn{3}{|l|}{ Strains } \\
\hline \multicolumn{3}{|l|}{ Mesorhizobia } \\
\hline R7A & Field reisolate of ICMP 3153 & Sullivan et al. (1995) \\
\hline $\mathrm{CJ} 3$ & Nonsymbiotic Mesorhizobium strains & Sullivan et al. (1996) \\
\hline \multicolumn{3}{|c|}{ - } \\
\hline HB101 & pro leu thi gal lacY recA str hsdD hsdM & Boyer \& Roulland-Dussoix (1969) \\
\hline $\mathrm{R} 872$ & bioF3 & Cleary \& Campbell (1972) \\
\hline $\mathrm{R} 875$ & bioB17 & Cleary \& Campbell (1972) \\
\hline R877 & bioD19 & Cleary \& Campbell (1972) \\
\hline $\mathrm{R} 878$ & bioC18 & Cleary \& Campbell (1972) \\
\hline $\mathrm{R} 879$ & bioA24 & Cleary \& Campbell (1972) \\
\hline BM7086 & $\Delta(m a l-b i o H) g a l$ & Hatfield et al. (1969) \\
\hline \multicolumn{3}{|l|}{ Plasmids } \\
\hline pLAFR1 & Broad-host-range cosmid, $\mathrm{Tc}^{\mathrm{r}}$ & Friedman et al. (1982) \\
\hline pIJ3200 & Broad-host-range cosmid, $\mathrm{Tc}^{\mathrm{r}}$ & Liu et al. (1990) \\
\hline pRK2013 & rep (colE1), $\mathrm{Mob}^{+} \mathrm{Tra}^{+} \mathrm{Km}^{\mathrm{r}}$ & Ditta et al. (1980) \\
\hline pPH1JI & IncP plasmid, $\mathrm{Gm}^{\mathrm{r}}$ & Hirsch (1979) \\
\hline pML122 & Broad-host-range expression vector, $\mathrm{Gm}^{\mathrm{r}}$ & Labes et al. (1990) \\
\hline pBluescript II KS & $\operatorname{lac} Z \alpha \mathrm{Ap}^{\mathrm{r}}$ & Stratagene \\
\hline pUC19 & $\operatorname{lac} Z \alpha \mathrm{Ap}^{\mathrm{r}}$ & Yanisch-Perron et al. (1985) \\
\hline p239 & pUC19 containing the $n p t I I$ gene from Tn5 & This study \\
\hline p637 & pLAFR 1 containing a $23.14 \mathrm{~kb}$ region of the $\mathrm{R} 7 \mathrm{~A}$ symbiosis island & This study \\
\hline p961 & pBluescript II KS containing a $6.82 \mathrm{~kb} P v u \mathrm{II}$ fragment of p637 & This study \\
\hline p962 & $\begin{array}{l}\text { pBluescript II KS containing the insert of p961 in the opposite } \\
\text { orientation }\end{array}$ & This study \\
\hline p963 & pBluescript II KS containing a $5.90 \mathrm{~kb}$ Aat II-PvuII fragment of p637 & This study \\
\hline p964 & $\begin{array}{l}\text { pBluescript II KS containing the insert of p963 in the opposite } \\
\text { orientation }\end{array}$ & This study \\
\hline p995 & pIJ3200 containing insert from p961 & This study \\
\hline p996 & pIJ3200 containing a $5.90 \mathrm{~kb}$ Aat II-PvuII fragment of p637 & This study \\
\hline p997 & pIJ3200 containing a $6.24 \mathrm{~kb}$ SpeI-PvuII fragment of p637 & This study \\
\hline p1013 & pUC19 containing a $B g l$ II (end-filled)-BamHI fragment of p637 & This study \\
\hline p1015 & pML122 containing a HindIII-BamHI fragment from p1013 & This study \\
\hline pBIO131 & pUC9 containing the B. subtilis bioI gene & Bower et al. (1996) \\
\hline pBIO403 & pCL1921 containing the $B$. subtilis bioW gene & Bower et al. (1996) \\
\hline
\end{tabular}

lated with 20-90 c.f.u. and incubated under controlled conditions as described by Streit et al. (1996). Roots were harvested $10 \mathrm{~d}$ post-inoculation and ground in $1 \mathrm{ml}$ sterile distilled water with a Dounce homogenizer. Rhizobia were enumerated by plating dilutions on G/RDM media. For dual inoculation experiments where R7A was compared to R7A::Tn5-5, 50 colonies were patched from G/RDM plates used for total enumeration onto G/RDM containing neomycin to determine the ratio of mutant to wild-type.

\section{RESULTS}

\section{Identification of genes required for nicotinate mononucleotide and biotin syntheses}

We have previously reported that all seven nonsymbiotic mesorhizobial strains isolated (CJ1-CJ7) were auxotrophic for biotin and thiamin and all but CJ5 were auxotrophic for nicotinate (Sullivan et al., 1996). A clone, p637, from a pLAFR1 cosmid library of strain R7A (Sullivan \& Ronson, 1998) was identified that complemented the nonsymbiotic Mesorhizobium strain CJ3 for the requirements for nicotinate and biotin but not thiamin. Hybridization of the cosmid DNA to symbiotic and nonsymbiotic strains showed that it contained DNA from the symbiosis island (data not shown).

The nucleotide sequence of the insert in p637 was determined, and a $13.2 \mathrm{~kb}$ region containing potential vitamin loci was analysed (Fig. 1). Of 12 ORFs encoding proteins larger than 60 amino acids identified, 11 showed similarity to sequences in the databases (Table 2). The deduced amino acid sequences of $\operatorname{nad} A, B$ and $C$ were similar to those of the nadA, $B$ and $C$ gene products which constitute the pathway for NMN synthesis in $E$. coli (Penfound \& Foster, 1996). Genes required for biotin synthesis identified on the basis of the similarity of their products to E. coli orthologues were $b i o B, F, D$ and $A$. The p637 genes were coupled by overlapping stop and start codons, suggesting that they are trans- 


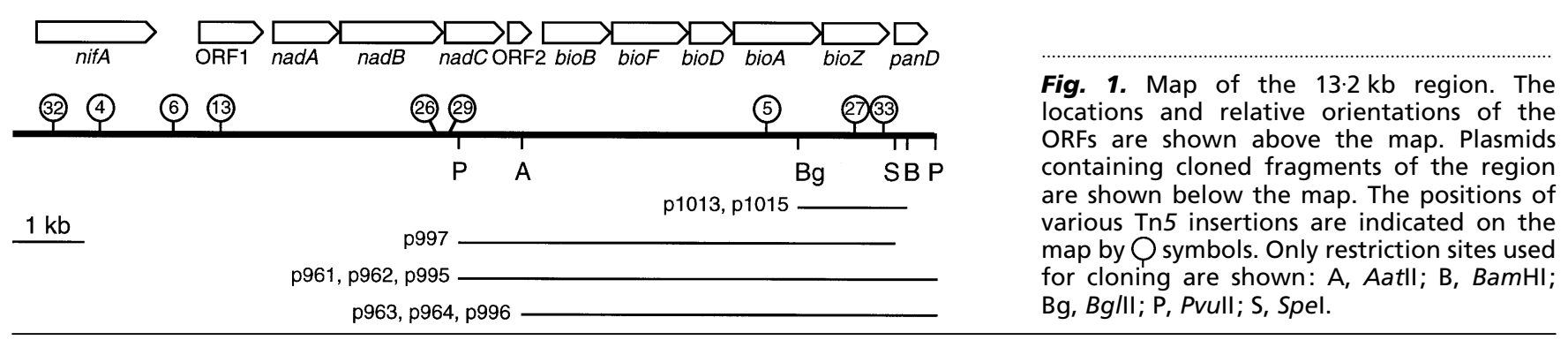

Table 2. Sequence similarities to predicted gene products

Percentage identities and similarities were derived from deduced gene products of ORFs using BLAST 2.0 (Altschul et al., 1997).

\begin{tabular}{|c|c|c|c|c|c|c|}
\hline ORF & Coordinates & $\begin{array}{l}\text { Length } \\
(\text { aa) }\end{array}$ & $\begin{array}{l}\text { Degree of } \\
\text { similarity* }\end{array}$ & Organism $\dagger$ & Putative function & Accession no. \\
\hline nifA & 233-2044 & 603 & $65 / 76 ; 27-601$ & $\begin{array}{l}\text { Bradyrhizobium } \\
\text { japonicum }\end{array}$ & nif-specific regulator & CAA29530 \\
\hline ORF1 & $2618-3577$ & 319 & $46 / 62 ; 22-316$ & $\begin{array}{l}\text { Neisseria } \\
\text { meningitidis }\end{array}$ & Unknown & AAF40835 \\
\hline $\operatorname{nad} A$ & $3642-4616$ & 324 & $32 / 50 ; 1-322$ & E. coli & Quinolinate synthetase & BAA35409 \\
\hline $\operatorname{nadB}$ & $4613-6154$ & 513 & $38 / 51 ; 13-481$ & E. coli & L-Aspartate oxidase & BAA02446 \\
\hline nadC & $6156-7037$ & 293 & $41 / 58 ; 19-280$ & E. coli & Nicotinate-nucleotide pyrophosphorylase & AAC36922 \\
\hline ORF2 & $7048-7395$ & 115 & None detected & & Unknown & \\
\hline bioB & $7542-8537$ & 331 & $59 / 75 ; 18-325$ & E. coli & Biotin synthetase & AAC73862 \\
\hline bioF & $8534-9673$ & 379 & $36 / 53 ; 28-372$ & E. coli & 7-Keto-8-aminopelargonic acid synthase & AAA23516 \\
\hline bioD & $9670-10305$ & 212 & $31 / 47 ; 1-158$ & E. coli & Dethiobiotin synthase & AAA23518 \\
\hline bioA & $10305-11570$ & 421 & $38 / 54 ; 3-413$ & E. coli & 7,8 Diaminopelargonic acid aminotransferase & AAD19178 \\
\hline \multirow[t]{2}{*}{ bioZ } & $11567-12550$ & 327 & $41 / 55 ; 1-322$ & $\begin{array}{l}\text { Streptomyces } \\
\text { coelicolor }\end{array}$ & $\begin{array}{l}\text { Pr. } \beta \text {-ketoacyl-acyl carrier protein synthase } \\
\text { III }\end{array}$ & CAA16179 \\
\hline & & & $34 / 54 ; 5-325$ & E. coli FabH & $\beta$-Ketoacyl-acyl carrier protein synthase III & AAA23749 \\
\hline pand & $12609-13061$ & 150 & $40 / 67 ; 1-111$ & E. coli & Aspartate 1-decarboxylase & P31664 \\
\hline
\end{tabular}

* Percentage identity/percentage similarity over given range of amino acids.

† Similarities to E. coli orthologue given where available.

cribed as a single operon. The start codon of a fifth ORF, bioZ, overlapped the stop codon of bioA. The deduced amino acid sequence of bio $Z$ showed similarity to $\beta$ ketoacyl-acyl carrier protein synthases (KAS IIIs) from several bacterial species, including the $\mathrm{fabH}$ gene product of E. coli (Table 2; Fig. 2). The deduced amino acid sequences of nif $A$ and panD showed similarity with the NifA protein required for regulation of several nif and fix genes in nitrogen-fixing bacteria, and the PanD protein required for pantothenate biosynthesis, respectively. The translated product of ORF1 showed strong sequence similarity over its entire length with the product of a gene of unknown function from Neisseria meningitidis that is flanked by nadA and nadC in that organism (Table 2).

\section{Tn5 mutagenesis}

To confirm the function of the genes on p637 identified by sequence analysis, several Tn 5 mutants of R7A were created by marker exchange using a selection of p637:: Tn5 insertions. The precise location of the insertions was determined by sequence analysis using a
Tn5-specific primer (Fig. 1). Mutants in nadB (Tn5-26) and nadC (Tn5-29) were nicotinate auxotrophs while mutants in bioA (Tn5-5) and bioZ (Tn5-27 and Tn5-33) grew poorly on solid media lacking biotin. Addition of avidin, a protein that binds biotin with high affinity, to solid media at $10 \mathrm{ng} \mathrm{ml}^{-1}$ completely abolished growth of mutants Tn5-5, Tn5-27 and Tn5-33, whereas growth of R7A was only slightly impaired. These results indicate that mutants Tn5-5, Tn5-27 and Tn5-33 were biotin auxotrophs. Insertions in ORF1 and nifA had no effect on bacterial growth, while insertions were not obtained in $\operatorname{nadA}, \mathrm{ORF} 2$, bioBFD or panD. All of the Tn5 mutants were $\mathrm{Nod}^{+} \mathrm{Fix}^{+}$, with the exception of the nifA mutants Tn5-4 and Tn5-32, which were Fix ${ }^{-}$.

\section{Complementation studies with $M$. loti bio genes}

The $\mathrm{Bio}^{-}$phenotype of the R7AbioZ::Tn5 strains implies that bio $Z$ is required for synthesis of the biotin precursor pimeloyl-CoA, as only the bio $A, B, D$ and $F$ genes are required for the synthesis of biotin from pimeloyl-CoA (Demoll, 1996). In E. coli, the bioC and bioH genes are involved in pimeloyl-CoA synthesis 


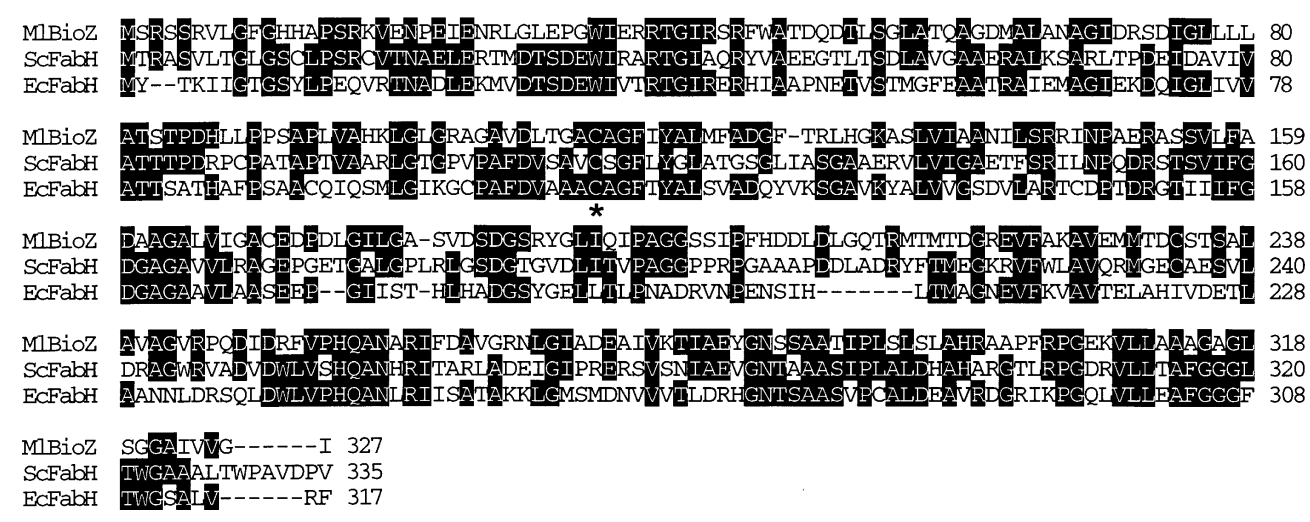

Fig. 2. Comparison of the deduced amino acid sequence of the symbiosis island bioZ gene (MIBioZ) with the sequence of the fabH gene products from Streptomyces coelicolor (ScFabH) (accession no. CAA16179) and E. coli (EcFabH) (accession no. AAA23749). The putative active site cysteine is marked with an asterisk.

Table 3. Complementation analysis of E. coli bio mutants with plasmid clones containing symbiosis island and B. subtilis bio genes

See Fig. 1 for map of clones and Table 1 for plasmid descriptions and strain designations of E. coli mutants. All strains were grown on M9 minimal medium containing $1 \mu \mathrm{g}$ avidin $\mathrm{ml}^{-1}$. +++ , Prototrophic; + , bradytrophic; - , auxotrophic; NT, not tested.

\begin{tabular}{|c|c|c|c|c|c|c|c|c|}
\hline Plasmid & Insert" & plac $\dagger$ & $\operatorname{bio} A 24$ & bioB17 & bioD19 & bioF3 & bioC18 & $\Delta b i o H$ \\
\hline p961 & ORF2-panD & + & +++ & + & +++ & +++ & - & - \\
\hline p962 & ORF2-panD & - & + & - & + & + & - & - \\
\hline p963 & bioB-panD & - & + & - & + & + & - & - \\
\hline p964 & bioB-panD & + & - & +++ & - & - & - & + \\
\hline p1013 & bioZ & + & NT & NT & NT & NT & $-\ddagger$ & +++ \\
\hline p1015 & bioZ & - & NT & NT & NT & NT & - & - \\
\hline pBIO131 & B. subtilis bioI & & NT & NT & NT & NT & +++ & +++ \\
\hline pBIO403 & B. subtilis bioW & & NT & NT & NT & NT & $+++\neq$ & $+++\neq$ \\
\hline
\end{tabular}

*First complete gene and last gene in plasmid insert.

† Orientation of plasmid insert relative to lac promoter.

$\ddagger$ Strains grown in the presence of neutralized pimelic acid.

(Demoll, 1996; Eisenberg, 1987). Complementation studies were carried out to determine if bioZ could complement E. coli bioC and bioH mutants, and to confirm the function of the R7A bioBFDA genes. Plasmid pBIO131 containing the Bacillus subtilis bioI gene was used as a positive control for the complementation of bioH and bioC mutants (Bower et al., 1996). Several plasmids that differed in their symbiosis island gene complement and the orientation of the genes with respect to the vector lac promoter were constructed (Fig. 1 ; Table 1). The results suggested that variations in the level of expression of the R7A bio operon from the various constructs influenced their ability to complement the E. coli bio mutants. E. coli bio $A, B, D, F$ and $H$ mutants were complemented by at least one construct containing the entire symbiosis island bio operon, while bio $\mathrm{Z}$ alone complemented the E. coli bioH mutant but not the bioC mutant (Table 3).

The bioW gene from Bacillus sphaericus and B. subtilis encodes a pimeloyl-CoA synthetase that utilizes pimelic acid as a substrate, and the gene is able to complement E. coli bioH and bioC mutants in the presence of neutralized pimelic acid at $30 \mu \mathrm{g} \mathrm{ml}^{-1}$ (Bower et al., 1996; Gloeckler et al., 1990). To determine if BioZ has a similar activity to BioW, the E. coli bioC mutant was transformed with p1013 and plated on media lacking biotin and containing $30 \mu \mathrm{g}$ neutralized pimelic acid $\mathrm{ml}^{-1}$. Plasmid pBIO403 containing the $B$. subtilis bioW gene was also used. pBIO403 but not p1013 complemented the bioC mutant in the presence of pimelic acid (Table 3).

In order to further confirm a role for bioZ in biotin synthesis in R7A, the bioZ gene was subcloned from p1013 as a BamHI-HindIII fragment into the broadhost-range expression vector pML122 to produce plasmid p1015 (Table 1). This plasmid restored the ability of R7A : : Tn5-27 to grow on biotin-free G/RDM containing avidin.

Plasmids p637::Tn5-5, p637:: Tn5-27 and p637:: Tn5- 
33 did not convert CJ3 to biotin prototrophy, confirming that bioA and bio $Z$ are required for biotin synthesis in M. loti. To determine whether ORF2 or panD, which flank the bio operon, were also required, regions of p637 were first cloned into pBluescript II KS and subsequently subcloned into pIJ3200 using suitable restriction sites to produce p995, p996 and p997 (Table 1; Fig. 1). These plasmids converted CJ3 to biotin prototrophy, indicating that neither ORF2 nor panD is required for biotin synthesis in CJ3.

\section{Growth-room rhizosphere colonization studies}

Five rhizosphere competition experiments, each with five replicates, were carried out using modified Leonard jars placed in a growth room. Treatments comprised R7A alone, R7A:: Tn5-5 (bio A:: Tn5) alone, and a 1:1 mix of the two strains. Inocula were prepared by washing and diluting $48 \mathrm{~h}$ cultures $10^{5}$-fold to give 20-120 c.f.u. per treatment. Between $10^{5}$ and $10^{7}$ bacteria were recovered from each root harvested $10 \mathrm{~d}$ postinoculation, indicating that the bacteria had undergone 12-18 doublings. No differences in the abilities of the two strains to colonize the $L$. corniculatus rhizosphere were detected (R7A, $\log _{10} 4 \cdot 7 \pm 1 \cdot 2 ;$ R7AbioA:: Tn5, $\log _{10} 5 \cdot 3 \pm 1 \cdot 1 ; 1: 1 \mathrm{mix}, \log _{10} 5 \cdot 4 \pm 1 \cdot 0$, with each strain equally represented).

\section{DISCUSSION}

We have shown that an acquired genetic element required for symbiosis, the $M$. loti symbiosis island, contains structural operons required for the biosyntheses of biotin and NMN closely linked to nifA, a symbiotic activator of nif and fix genes (Fischer, 1994). The bio operon contains a novel gene, bioZ, that provides insight into a poorly understood step in the pathway of biotin synthesis. In addition, the location of the bio operon on an acquired genetic element may explain the observed diversity of rhizobia with respect to biotin auxotrophy.

Biotin is an essential cofactor for carboxylase enzymes and in E. coli and B. subtilis is synthesized from pimeloyl-CoA via four enzymic steps involving the products of the bio $A, B, D$ and $F$ genes. Steps involved in pimeloyl-CoA synthesis are less well-characterized but differ between the two organisms. The functions of the symbiosis island bio $A, B, D$ and $F$ genes were confirmed by their ability to complement respective $E$. coli bio mutants. However, orthologues of bioZ are not found amongst the known bio genes of other organisms.

Variation in the growth of complemented E. coli bio mutants that was dependent on the particular plasmid used for complementation was observed. For example, p961 complemented the E. coli bioA, bioD and bioF mutants to wild-type growth; however, the E. coli bioB mutant was bradytrophic when complemented with this plasmid. In contrast, the E. coli bioB mutant was fully complemented by p964 containing the entire bio operon fused to the E. coli lacZ promoter, but p964 did not complement the bioA, $D$ or $F$ mutants. Plasmid p964 was also the only plasmid containing the entire symbiosis island bio operon that complemented the bioH mutant, albeit to bradytrophic growth, whereas p1013 restored the mutant to wild-type growth. Problems with complementation and/or viability associated with the expression of bioB have been observed in other organisms, including E. coli and Serratia marcescens (Ifuku et al., 1995; Levy-Schil et al., 1993; Sakurai et al., 1993). Moreover, S. meliloti strains expressing the E. coli bio operon show reduced viability (Streit \& Phillips, 1996).

Pimeloyl-CoA is a seven-carbon thioester that is the first dedicated intermediate in the biotin biosynthetic pathway. B. sphaericus and B. subtilis both contain a pimeloyl-CoA synthetase, encoded by bioW, which condenses pimelic acid with CoA to form pimeloylCoA. bioW complements both E. coli bioC and bioH mutants in the presence of pimelic acid (Bower et al., 1996; Gloeckler et al., 1990). In E. coli, pimeloyl-CoA synthesis does not involve pimelic acid as an intermediate. Instead, a synthetic mechanism similar to a fatty acid synthase reaction involving the condensation of three malonyl-CoA molecules has been suggested based on radiolabelling studies (Ifuku et al., 1994; Sanyal et al., 1994). The symbiosis island bioZ gene cannot complement an E. coli bioC mutant, even in the presence of free pimelic acid, and therefore its product does not appear to act as a pimeloyl-CoA synthetase; however, it does complement bioH mutants.

The strong sequence similarity of BioZ to $\beta$-ketoacylacyl carrier protein synthase III $(\mathrm{FabH})$ suggests that BioZ is a fatty acid synthase. FabH forms part of the dissociated (type II) fatty acid synthase system in bacteria. It catalyses the first step in fatty acid synthesis, the condensation of an acetyl-CoA starter unit with malonyl-ACP to form acetoacetyl-ACP. The enzyme also has an acetyl-CoA: ACP transacylase activity which involves the interconversion of acetyl-ACP and acetylCoA (Tsay et al., 1992). Condensing enzymes such as $\mathrm{FabH}$ function via an acyl-enzyme intermediate attached as a thioester to an active cysteine residue. The active-site cysteine of FabH is conserved in BioZ (Fig. 2). It seems possible that BioZ is involved in a condensation reaction perhaps involving incorporation of a thioester with an odd number of carbon atoms leading to synthesis of pimeloyl-ACP, and also in its transacylation to pimeloyl-CoA. E. coli FabH, which has been shown to carry out a condensation reaction of propionyl-CoA with malonyl-ACP to produce fatty acids with odd numbers of carbon atoms (Heath \& Rock, 1996), may carry out similar steps to BioZ but have a narrower specificity for its transacylation reaction, accounting for the requirement for $\mathrm{BioH}$ in E. coli. In this model, BioC would be required for the synthesis of one of the substrates for the initial condensation reaction. It of course remains to be determined whether mesorhizobia contain a bioC orthologue elsewhere in their genome.

The presence of vitamin synthesis genes on the symbiosis island suggests that they may be required for, or augment, the symbiotic interaction. However, mutants 
with Tn5 insertions in the NMN and biotin synthesis operons were unaffected in nodulation or nitrogen fixation, and the bioA mutant was unaffected in rhizosphere colonization. These results are consistent with the findings that some rhizobia are natural biotin auxotrophs (Graham, 1963) and that nonsymbiotic mesorhizobia were present in the rhizosphere of $L$. corniculatus grown in the field (Sullivan et al., 1996). However, they are contrary to a previous study which reported that $S$. meliloti biotin auxotrophs competed very poorly with the parent strain (Streit et al., 1996). It is possible that the difference in the results reflects the different host plants or rhizobial species used.

Despite the lack of an obvious symbiotic role, the presence of vitamin synthesis operons on the island strongly suggests that they can contribute to a successful plant-microbe interaction. Conversely, the lack of the operons may benefit the nonsymbiotic mesorhizobia. Acquired genes usually confer a selective advantage only under specific conditions and may be prone to loss under other environmental conditions. The vitamin synthesis genes may have been lost from the nonsymbionts if they were detrimental to the rhizobia for maintaining a saprophytic lifestyle in the absence of the host. For example, vitamin starvation may enable the bacteria to adopt a stress-resistant dormant state, which would only be alleviated in the presence of an environment conducive to growth. In this regard, the nonsymbiotic rhizobia may use the presence of vitamins as an indicator of the presence of a plant root. Certainly the presence of the bio and nad genes on the symbiosis island extends the range of 'house-keeping' genes known to be encoded on accessory genetic elements.

\section{ACKNOWLEDGEMENTS}

We thank Megan Hall for technical assistance. This work was supported by a grant from the Marsden Fund administered by the Royal Society of New Zealand.

\section{REFERENCES}

Altschul, S. F., Madden, T. L., Schaffer, A. A., Zhang, J. H., Zhang, Z., Miller, W. \& Lipman, D. J. (1997). Gapped BLAST and PSI-BLAST: a new generation of protein database search programs. Nucleic Acids Res 25, 3389-3402.

Beringer, J.E. (1974). $\mathrm{R}$ factor transfer in Rhizobium leguminosarum. J Gen Microbiol 84, 188-198.

Besemer, J. \& Borodovsky, M. (1999). Heuristic approach to deriving models for gene finding. Nucleic Acids Res 27, 3911-3920.

Bower, S., Perkins, J. B., Yocum, R. R., Howitt, C. L., Rahaim, P. \& Pero, J. (1996). Cloning, sequencing, and characterization of the Bacillus subtilis biotin biosynthetic operon. J Bacteriol 178, 4122-4130.

Boyer, H. W. \& Roulland-Dussoix, D. (1969). A complementation analysis of the restriction and modification of DNA in Escherichia coli. J Mol Biol 41, 459.

de Bruijn, F. J. \& Lupski, J. R. (1984). The use of transposon Tn5 mutagenesis in the rapid generation of correlated physical and genetic maps of DNA segments cloned into multicopy plasmids - a review. Gene 27, 131-149.
Cleary, P. P. \& Campbell, A. (1972). Deletion and complementation analysis of the biotin gene cluster of Escherichia coli. J Bacteriol 112, 830-839.

Demoll, E. (1996). Biosynthesis of biotin and lipoic acid. In Escherichia coli and Salmonella: Cellular and Molecular Biology, pp. 704-709. Edited by F. C. Neidhardt and others. Washington, DC: American Society for Microbiology.

Ditta, G. S., Stanfield, D., Corbin, D. \& Helinski, D. R. (1980). Broad host range DNA cloning system for Gram-negative bacteria : construction of a gene bank of Rhizobium meliloti. Proc Natl Acad Sci U S A 77, 7347-7351.

Dreyfus, B. L., Elmerich, C. \& Dommergues, Y. R. (1983). Free living Rhizobium strain able to grow on $\mathrm{N} 2$ as the sole nitrogen source. Appl Environ Microbiol 45, 711-713.

Eisenberg, M. A. (1987). Biosynthesis of biotin and lipoic acid. In Escherichia coli and Salmonella typhimurium: Cellular and Molecular Biology, pp. 544-550. Edited by F. C. Neidhardt and others. Washington, DC: American Society for Microbiology.

Finan, T. M., Kunkel, B., De Vos, G. F. \& Signer, E. R. (1986). Second symbiotic megaplasmid in Rhizobium meliloti carrying exopolysaccharide and thiamine synthesis genes. J Bacteriol 167, 66-72.

Fischer, H. M. (1994). Genetic regulation of nitrogen fixation in rhizobia. Microbiol Rev 58, 352-386.

Friedman, A. M., Long, S. R., Brown, S. E., Buikema, W. J. \& Ausubel, F. M. (1982). Construction of a broad host range cosmid cloning vector and its use in genetic analysis of Rhizobium mutants. Gene 18, 289-296.

Gloeckler, R., Ohsawa, I., Speck, D. \& 7 other authors (1990). Cloning and characterization of the Bacillus sphaericus genes controlling the bioconversion of pimelate into dethiobiotin. Gene 87, 63-70.

Graham, P. H. (1963). Vitamin requirements of root nodule bacteria. J Gen Microbiol 30, 245-248.

Hatfield, D., Hofnung, M. \& Schwartz, M. (1969). Genetic analysis of the maltose A region in Escherichia coli. J Bacteriol 98, 559-567.

Heath, R. J. \& Rock, C. O. (1996). Roles of the FabA and FabZ beta-hydroxyacyl-acyl carrier protein dehydratases in Escherichia coli fatty acid biosynthesis. J Biol Chem 271, 27795-27801.

Hirsch, P. R. (1979). Plasmid-determined bacteriocin production by Rhizobium leguminosarum. J Gen Microbiol 113, 219-228.

Ifuku, O., Miyaoka, H., Koga, N., Kishimoto, J., Haze, S., Wachi, Y. \& Kajiwara, M. (1994). Origin of carbon atoms of biotin: C-13NMR studies on biotin biosynthesis in Escherichia coli. Eur J Biochem 220, 585-591.

Ifuku, O., Koga, N., Haze, S., Kishimoto, J., Arai, T. \& Wachi, Y. (1995). Molecular analysis of growth inhibition caused by overexpression of the biotin operon in Escherichia coli. Biosci Biotechnol Biochem 59, 184-189.

Labes, M., Puhler, A. \& Simon, R. (1990). A new family of RSF1010-derived expression and lac-fusion broad-host-range vectors for Gram-negative bacteria. Gene 89, 37-46.

Levy-Schil, S., Debussche, L., Rigault, S. \& 7 other authors (1993). Biotin biosynthetic pathway in recombinant strains of Escherichia coli overexpressing bio genes: evidence for a limiting step upstream from KAPA. Appl Microbiol Biotechnol 38, 755-762.

Liu, Y. N., Tang, J. L., Clarke, B. R., Dow, J. M. \& Daniels, M. J. (1990). A multipurpose broad host range cloning vector and its use to characterize an extracellular protease gene of Xanthomonas campestris pathovar campestris. Mol Gen Genet 220, $433-440$. 
Miranda-Rios, J., Morera, C., Taboada, H., Davalos, A., Encarnacion, S., Mora, J. \& Soberon, M. (1997). Expression of thiamin biosynthetic genes (thiCOGE) and production of symbiotic terminal oxidase cbb3 in Rhizobium etli. J Bacteriol 179, 6887-6893.

Penfound, T. \& Foster, J. W. (1996). Biosynthesis and recycling of NAD. In Escherichia coli and Salmonella: Cellular and Molecular Biology, pp. 721-730. Edited by F. C. Neidhardt and others. Washington, DC: American Society for Microbiology.

Ronson, C. W., Nixon, B. T., Albright, L. M. \& Ausubel, F. M. (1987). Rhizobium meliloti ntrA (rpoN) gene is required for diverse metabolic functions. J Bacteriol 169, 2424-2431.

Ruvkun, G. B. \& Ausubel, F. M. (1981). A general method for sitedirected mutagenesis in prokaryotes. Nature 289, 85-88.

Sakurai, N., Imai, Y., Masuda, M., Komatsubara, S. \& Tosa, T. (1993). Molecular breeding of a biotin-hyperproducing Serratia marcescens strain. Appl Environ Microbiol 10, 3225-3232.

Sambrook, J., Fritsch, E. F. \& Maniatis, T. (1989). Molecular Cloning: a Laboratory Manual, 2nd edn. Cold Spring Harbor, NY : Cold Spring Harbor Laboratory.

Sanyal, I., Lee, S. L. \& Flint, D. H. (1994). Biosynthesis of pimeloylCoA, a biotin precursor in Escherichia coli, follows a modified fatty acid synthesis pathway: ${ }^{13} \mathrm{C}$-labeling studies. I Am Chem Soc 116, 2637-2638.

Streit, W. R. \& Phillips, D. A. (1996). Recombinant Rhizobium meliloti strains with extra biotin synthesis capability. Appl Environ Microbiol 62, 3333-3338.

Streit, W. R., Joseph, C. M. \& Philips, D. A. (1996). Biotin and other water-soluble vitamins are key growth factors for alfalfa root colonisation by Rhizobium meliloti 1021. Mol PlantMicrobe Interact 9, 330-338.

Sullivan, J. T. \& Ronson, C. W. (1998). Evolution of rhizobia by acquisition of a $500-\mathrm{kb}$ symbiosis island that integrates into a phetRNA gene. Proc Natl Acad Sci US A 95, 5145-5149.

Sullivan, J. T., Patrick, H. N., Lowther, W. L., Scott, D. B. \& Ronson, C. W. (1995). Nodulating strains of Rhizobium loti arise through chromosomal symbiotic gene transfer in the environment. Proc Natl Acad Sci U S A 92, 8985-8989.

Sullivan, J. T., Eardly, B. D., van Berkum, P. \& Ronson, C. W. (1996). Four unnamed species of nonsymbiotic rhizobia isolated from the rhizosphere of Lotus corniculatus. Appl Environ Microbiol 62, 2818-2825.

Tsay, J. T., Oh, W., Larson, T. J., Jackowski, S. \& Rock, C. O. (1992). Isolation and characterization of the beta-ketoacyl-acyl carrier protein synthase-III gene $(\mathrm{fabH})$ from Escherichia coli K-12. J Biol Chem 267, 6807-6814.

Vincent, J. M. (1970). A Manual for the Practical Study of Root Nodule Bacteria. Oxford: Blackwell Scientific Publications.

Wilson, J. B. \& Wilson, P. W. (1942). Biotin as a growth factor for rhizobia. J Bacteriol 43, 329-341.

Yanisch-Perron, C., Vieira, J. \& Messing, J. (1985). Improved M13 phage cloning vectors and host strains: nucleotide sequences of the M13mp18 and pUC19 vectors. Gene 33, 103-109.

Received 29 December 2000; accepted 29 January 2001. 